europhysics news extra - EPS information EurophysNet at http://epswww.epfl.ch/

\section{European Physical Society}

EPS Secretariat, P. O. Box 69,

H-1213 Petit-Lancy 2, Geneva

elephone: +41-22-7931130

elefax: +41-22-7931317

-mail:eps@cern.ch

NWW: http://epswww.epfl.ch/

PS counts among its members some 4000 ndividual Ordinary Members and 37 National Member Societies throughout Europe whose nembers participate in EPS activities.

\section{Managing Editor}

P.G. Boswell, EPS Geneva

E-mail: peter.boswell@cern.ch

\section{Subscriptions}

ISSN: 0531-7479

Volume 27: 6 issues will appear in 1996 . Recommended annual subscription prices nstitutions: DM 160.-; individuals DM 98.pecial rate for new individual subscribers: $\mathrm{OM} 78$,- for one year. All prices plus carriage. EPS Individual Ordinary Members receive Europhysics News free of charge. Members of EPS National Member Societies except the German Physical Society and the Institute of hysics, UK, receive Europhysics News hrough their society.

Subscriptions can either be placed via an agent or sent directly to:

Springer-Verlag, Postfach 311340

D-10643 Berlin, Germany

Telephone: $+49-30-8207-358$

Telefax: $+49-30-82$ o7- 448

E-mail: subscriptions@springer.de

Cancellation must be received by September 30 to take effect the following year.

\section{Production}

PRODUserv

Springer Produktionsgesellschaft

3050 Journal Production Department

L. Grenzdörfer, Heidelberger Platz 3

D-14197 Berlin, Germany

Telephone: $+49-30-8207750$

Telefax: $+49-30-82$ o7 440

E-mail: grenzdoerfer@springer.de

\section{Advertisements}

Springer Verlag

E. Lückermann, U. Evert

D-14197 Berlin, Germany

Telephone: $+49-30-8207733$

Telefax: $+49-30-8207300$

Advertising is charged according to space and position, pro rata based on DM 3800 .- for a full page, black and white. Advertising rates on request. Discounts for EPS Associate Members.

Deadline for orders: on request (normally four weeks before publication).

\section{Printer}

Universitätsdruckerei H. Stürtz AG, Würzburg

\section{More Structure}

Having started life 26 years ago as an eight-page quarterly sent to individual members, Europhysics News today enjoys an enlarged distribution and a new look following the cooperation with Springer. The move to a variety of rubriques continues under an expanded Editorial Board, helped by Division and Group correspondents to ensure that readers are kept abreast of the latest developments in physics. The Board will aim for about eight rubriques in each issue, some of which may not be repeated every time; roughly one-third of the editorial pages will feature technical items and highlights.

The Board is actively seeking contributors covering a wide range of non-technical topics. This issue's contributions on electronic publishing, donor agencies, a European education forum, and physics in the Czech Republic illustrate some of the opportunities for comment and opinion besides the all-important Letters to the Editor section, which the President (page 4) hopes will be become a lively forum for critical discussion.

An important topic that receives little attention in this particular issue is physics and industry. While the President points out that it makes little sense to talk of physics for this and physics for that, a special rubrique will offer the opportunity to focus on issues relating to physicists working, and aiming to work, with and for industry.

The on-line Europhysics News Extra edition which, broadly speaking, contains most of the items published in Europhysics News backed up by secondary materials and links to other sources, continues as some readers clearly seek instant electronic access to wellstructured, timely information, some of which is specialised and voluminous. A major effort will be made to use electronic publishing techniques to consolidate information presently gathered and redistributed by several organizations (lists of meetings, new books and conference proceedings are obvious targets). Another aim is to incorporate ENE into the increasingly sophisticated electronic services being offered by Springer, and indeed by most physics publishers and organizations (page 25).

Attention will given more often to developments in various regions because, as the Presidents' meeting in Budapest illustrated (page 35), some parts of Europe have particular messages, for both internal circulation and dissemination elsewhere, which can best be passed by focussing information and news on a regional basis. Included within this perspective are developments in the European Union. With the increasing desire for physicists to seek a closer European integration (page 35) it is now wise to cover developments in Brussels from several perspectives, as on pages 27 and 34 giving reports on both more mundane, but useful, aspects as well as relatively esoteric political issues.

In the final analysis, it is readers who will have the last word about the need and format for more structured editorial (a readership survey is to be organized once the new production arrangements have settled down). From the impressum, they will also note that Springer now handles advertisments, production, subscriptions and distribution.

P.G. Boswell
VIS J. Schwarz

Hindenburgstraße 12

D-76332 Bad Herrenalb

Phone: $+49(0) 7083 / 51833$

Fax: $\quad+49(0) 7083 / 51925$

ask for more information ! 